\title{
Towards a social theory of acceleration: Time, modernity, critique
}

Filip Vostal

\section{(2) OpenEdition}

\section{Journals}

Electronic version

URL: http://journals.openedition.org/ress/2893

DOI: $10.4000 /$ ress.2893

ISSN: 1663-4446

\section{Publisher}

Librairie Droz

\section{Printed version}

Date of publication: 27 November 2014

Number of pages: 235-249

ISBN: 978-2-600-01866-1

ISSN: 0048-8046

\section{Electronic reference}

Filip Vostal, «Towards a social theory of acceleration: Time, modernity, critique », Revue européenne des sciences sociales [Online], 52-2 | 2014, Online since 01 January 2018, connection on 19 April 2019 URL : http://journals.openedition.org/ress/2893; DOI : 10.4000/ress.2893 


\section{TOWARDS A SOCIAL THEORY OF ACCELERATION Time, modernity, critique \\ Filip Vostal (Prague, Centre for Science, Technology, and Society Studies, Institute of Philosophy, Academy of Sciences of the Czech Republic)}

\section{Rosa HARTMUT, 2013 (2005), Social Acceleration: A New Theory of Modernity, translated and introduced by Jonathan Trejo-Mathys, New York, Columbia University Press, 470 p.}

The English translation of Hartmut Rosa's book Beschleunigung: Die Veränderung de Zeitstrukturen in der Moderne (2005a) ${ }^{1}$ accounts for a long-awaited investigation of the causes, manifestations and consequences of acceleration ${ }^{2}$ : a frequently pronounced attribute of modernity; often, however, approached in a popular and impressionistic - rather than scholarly and social scientific - fashion. Even though many readers might, and probably will, intuitively consider the study to be yet another prophetic and epochalist account on a fashionable theme; after a careful reading of the introduction and first few pages they will be surprised to discover that the very opposite of their initial assumption is true. With Rosa's inquiry at the forefront, we are perhaps approaching a stage where the prevalent acceleration "zeitgeistology"-mostly associated with enigmatic yet oftentimes unintelligible work of Paul Virilio ${ }^{3}$ - in the social sciences will finally be surmounted. Moreover, Rosa's acceleration-centred study accounts for a highly sophisticated and rigorous theoretical contribution to contemporary critical social theorizing. Alongside briefly introducing the theory's grounding and outlining its structure, this review essay, rather than providing exhaustive overview of the entire theoretical scheme, will discuss selected features of Rosa's argument and formulate several polemical considerations borne therefrom.

By advancing a concept of social acceleration as the central explanatory and normative concern, Rosa pursues no less ambitious aim than to offer a new research programme, at the centre of which stands analysis of the temporal structure of modern society (Social Acceleration, p.26). Through this manoeuvre, Rosa strives to re-energize the relevance of critical social theory for understanding, explaining and critically engaging with the pathologies of the contemporary social world, and generally aims to place social criticism at the centre of sociological thought. The basis for such a programme is thus:

I The French translation of this book appeared as Accélération: Une critique sociale du temps (Rosa, 2013a).

2 Rosa's other works on acceleration include: Rosa, 2003; 2005b; 20I0a-translated to French (Rosa, 2012a) and German (Rosa, 2013b) -20l0b; 2012b; and Rosa \& Scheuerman, 2009.

3 However, Virilio's influence on social scientific investigations of acceleration remains important. As William Connolly writes: "It would be difficult to overstate the importance of Virilio to exploration of the effects of speed upon the late-modern condition. Everybody who engages the issue is indebted to him, even when they disagree with him profoundly" (2002, p. 177). 
modernization is not only taking shape in time but that it also means a transformation of time structures and horizons. Two conceptual moves underpin such a qualification.

Firstly, anchoring the acceleration-focused temporal perspective in the centre of social theory enables the coupling of a constitutive dualism in sociology: the tension between social actors and social systems (SA, p.4-5). Whilst temporal structures and horizons significantly co-shape subjective "action orientation and self-relations" (SA, p.5), simultaneously, according to Rosa, time also constitutes a self-standing aspect structuring individual lives "insofar as time, regardless of its social construction and systemic production, confronts actors as a 'natural fact' or a 'given"” (ibid.). Furthermore, similarly to Émile Durkheim and Norbert Elias, Rosa's social ontology stresses that the shifts in subjective time consciousness, experience and perception are dialectically related to the larger socio-cultural transformation: "the temporal structures of a given society are both cognitively and normatively binding as well as anchored deep within the personality structure that determines the habitus of individuals" (SA, p.6). Not only does transformation of the temporal structures of modern society reconfigure our relationship with each other and with ourselves, but it also affects how we relate to the physical and natural world we inhabit.

Secondly — and relatedly - Rosa reflects upon the difference between everyday (experiential) time, lifelong (biographical) time and historical (longue-durée) time and registers the inevitable tensions and incompatibilities that emerge as a result of their interplay. Here we encounter the crucial remark which indicates Rosa's explanatory position favouring the structural, rather than agentic, explanation of the acceleration phenomenon: "The rhythm, speed, duration and sequence of our activities and practices are almost never determined by us as individuals but rather almost always prescribed by the temporal patterns and synchronization requirements of society" (SA, p.9). Rosa, for instance, identifies an important modern temporal asymmetry between the abstract, fixed and external time patterns ("hours of operations, transportation schedules, institutional rhythms, time-regulating contracts, deadlines" [ibid.]) that characterize functionally differentiated and interdependent societies on the one hand, and the action or event time of individuals determined by different - often biological but also normative-temporal rhythms, on the other. The external "hidden temporal norms" (see also Zerubavel, 1985), with their structural preference for acceleration, form a dominant organizational mechanism significantly shaping and regulating individual schedules as well as social expectations about one's pacing.

Simultaneously, by focusing on acceleration, Rosa's account aims to bypass the long-evolving sociological investigations of social time, which he finds unsatisfactory as a selfstanding social scientific field (SA, p.2-I3). Rosa's other ambition is "to contribute to an adequate social-theoretical grasp of current social developments and problems in the context of the process of modernization and also the debate concerning a fracture in this process between a 'classical' age of modernity and a 'second' age of late or postmodernity 
[.... and] work out their ethical and political implications" (SA, p.4, emphasis original; see also p.I8-19, p.28I et seq.). The increasing speed at which social processes and experiences transpire marks the principal parameter, which characterizes present-day modernity and differentiates it from its predecessors. Rosa notes: "the acceleration that is a constitutive part of modernity crosses a critical threshold in 'late modernity' beyond which the demand for societal synchronization and social integration can no longer be met" (SA, p.20). This rupture-seen from a temporal perspective-and the resulting crises, pathologies and problems of socio-political and psychological character opens up the normatively underpinned framework upon which Rosa advances his theory.

\section{Acceleration as a keyword}

At the outset of the book, Rosa makes an important distinction: that there is a need to distinguish between the barely disputable social dynamization and intensification of social processes that characterize modernity, on the one hand, and the social discourses (and associated cultural criticism) they trigger, on the other. Both celebratory and negative reactions to the increasing speed of social life (ranging from Futurism to fast-food, or from bourgeois turtle walking flâneurs to Slow Food) have featured social development in the $19^{\text {th }}$ century western world as well as in the $2 \mathrm{I}^{\text {st }}$ century capitalist modernity marked by " $24 / 7$ markets and a global infrastructure for continuous work and consumption" (Crary, 2013, p.3). Rosa deals with the obligatory questions here: what is it in modern - and late modern-society that is actually accelerating? What is, in fact, acceleration? Before offering the general analytical framework, Rosa-without denying the early modern promise of speed (on that see Duffy, 2009; Kern, 2003; Tomlinson, 2007) —formulates a key principle: that acceleration has become quasi-autonomous dominant force with the power of generating negative consequences and socio-psychological pathologies. In other words, acceleration is not only a quantitative but also, importantly, a qualitative phenomenon ( $S A, \mathrm{p} .24)$.

Rosa argues that the existing conceptual and methodological resources in classical and contemporary sociology are conductive yet unsuitable (SA, p.46-48) to capturing acceleration. Therefore, there is a need for a categorical framework yielding systematic analysis of the causes, manifestations and consequences of the modern processes of acceleration $^{4}$. Drawing upon the classical sociological theories of modernization, the constitutive claim underpinning the acceleration theory is this: next to rationalization, individualization, differentiation, and commodification/domestication (of nature), acceleration accounts for a crucial, yet largely neglected, aspect of modernity and modernization.

4 Calls to recalibrate the parameters of social and political theorizing under the weight of epochal events is hardly news in the social sciences. Examples include Ulrich Beck's "cosmopolitan turn" in political and social sciences, Zygmunt Bauman's account on modernity and holocaust and even Alexis de Tocqueville's new political science for a new world. For a critical evaluation of epochalisms in sociology see Savage (2009). 
Rosa's key argument is to propose that, first, modernity can be understood as a process of acceleration as it infuses and structures all four aforementioned aspects characterizing modernity; or, simply put, it is "a central developmental principle of the temporal dimension of modernity” (SA, p.6I). Second, that there are modes of functioning, scope and implications of acceleration process, both on structural and on subjective levels. Third, once the conceptual connections are established the theory of social acceleration allows us to explain and interpret manifold social pathologies as acceleration-related issues, which, in turn, enables the re-vamping of critical theory with acceleration and time at its centre (see Rosa, 20I0a, p.67-97).

Adopting a diachronic perspective, technological-technical acceleration, the first analytical building-block, accounts for one of the most important aspects of modernity: "the story of acceleration to be told here describes the path from the steam engine to the utilization of hydraulic power and the combustion engine, on down to electricity and the technologies of industrial mass production and the assembly line, arriving finally at the microtechnologies of the computer age" (SA, p.73). It is beyond doubt that technologicallyinduced rates of communication, distribution, production, consumption, and circulation have been steadily intensifying for the past two hundred years. In late modernity, virtualization and digitalization of hitherto material processes allow prompt circulation and transmission and result in an unprecedented dynamization of socio-economic systems. Importantly, technological-technical acceleration alters (not determines) the subjective perception of time and space, which in turn affects and recuperates social relations (SA, p.97-I07) thus potentially generating ethical and political dilemmas. This category also includes goal-directed-technological-teleological-acceleration strategies (such as innovative techniques of production, organization, decision-making, administration, management). Additionally, Rosa deploys a range of evidence that convincingly illustrates how the economic logic of capitalism and associated technological development undoubtedly account for the key substantial drives of modern acceleration.

Acceleration of social change, the second category, is to be understood in a twofold way. First, it comprises the tempo of change in "practices and action orientation and [...] associational structure and patterns of relationship" (SA, p.74). Second, it also means that the rates of change themselves transform. The example capturing both levels is composed of an ever-faster implementation of ever-new socio-economic arrangements (such as audit mechanisms of measurement and surveillance pervasive, for instance, in the majority of "knowledge economy" workplaces) that are themselves designed to intensify specific actions, tasks, and executions integral to a particular profession/job . Yet Rosa faces

5 This feature is acutely apparent, for instance, in academic life: changes regulating work are happening ever-more frequently and it is often the case that the changes themselves are intended to speed-up specific processes (see SA, p.134; for inquiries into temporal shifts in academia see also Ylijoki, 20I3; Vostal, 2014). 
considerable difficulty in the argument construction: no consensus exists in the social sciences as to what counts as the definitive indicator of social change. Rosa, in turn, takes the initiative and provides series of conceptual justifications that help to qualify possibly relevant indicators constituting social change. A specific notion underpins such qualification. Drawing on Reinhart Koselleck and Herman Lübbe, Rosa says that the acceleration of social change can be defined "as an increase of the rate of decay of action-orienting experiences and expectations and as contraction of the time periods that determine the present of respective functional, value, and action spheres" (SA, p.76). Rosa holds that the technologically and socially mediated quantitative increase in the speed of change alters "qualitative shifts in the experience of time" (SA, p.304). Subsequently, the present seems to "shrink" and compress and, as a result, the rates of social and cultural obsolescence increase (see SA, p.74-78). One of the manifestations of such conditions is the emergence of what Rosa calls "slipping slopes" phenomena: "actors [in the late modern world] operate under conditions of permanent multidimensional change that make standing still by not acting or not deciding impossible" (SA, p.I I7). Readapting, updating, actualizing, and perpetual maintenance are now dominant behavioural necessities for realization of future options and even for the preservation of the existing condition. Flexibility, agility, multitasking, life-long education, and the continual need for improvement appear to be undisputable shibboleths of the late modern work place and personal life.

Even though it remains debatable as to whether "one is standing on slipping slopes in all realms of life" (SA, p.i 8), Rosa also holds that the widely reported levels of stress and time pressure are associated with individual and institutional imperatives of being permanently on-line, updated, available and sufficiently familiar with the latest tech gadgets and gizmos. These imperatives often form operational necessities: "in order to maintain one's position, to avoid lost opportunities, and to meet the requirements of synchronization, one has to constantly monitor and keep pace with changes in the social environment" (SA, p.306). The ability to process frequently changing digitalized information datasets and to quickly acquire electronic techniques of manipulation is now a standard requirement in fast digitally-mediated capitalism. Consequently, fast, agile, digital-savvy personalities and institutions are becoming dominant authorities - the "speed winners"-in manifold social terrains (see Bourdieu, 1998 [1996], p.28-30; Hassan, 2008, p.15-17)6.

The final part of Rosa's three-dimensional scheme, acceleration of the pace of life, explores specific experiential aspects of these fast personae. This conceptual category reflects upon the (late) modern impression that the world that we live in is getting ever-faster. Numerous qualitative accounts and studies in cultural history convincingly demonstrate

6 However, complex bureaucratic institutions are also characterized by inefficiency rigidity and statis (see SA, p.204; Tomlinson, 2007, p.6) and as a result are often diversely pressured to accelerate their operations: eliminated time lags, frictions and delays. I discuss Rosa's idea of dialectical relationship between constant need for speed and structural rigidity below. 
that this type of impression is recurrent for individual lifeworld experience in modernity, and in this sense this psycho-phenomenological attribute is barely a new observation. As among others, Simon Glezos (2012, p.3) notes that every generation perceives their age as unprecedentedly fast in relation to their predecessors. Nonetheless, what deserves attention is Rosa's approach to this experience and his theoretical investigation of it in the context of late modernity and in relation to the two previous categories. Rosa defines this experience as "the increase of episodes of action and/or experience per unit of time as a result of a scarcity of time resources" (SA, p.I2I). The final part of the definition is important as Rosa conceptualizes the acceleration of the pace of life as a result of involuntary and even oppressive aggregation of the speed of action and transformation of the time experience ( $S A$, p.I22). Individual actions, episodes and even experiences are, according to Rosa, increasingly compressed as a result of technological speed and the increasing social tempo of change. This is, indeed, associated with the increasing volume and number of pieces of information, commodities, impulses, contacts, channels, and connections one is either exposed to or engages with by necessity: a thorough engagement with a book or an academic journal, for instance, "decreases in lockstep with the increase in the number of relevant journals" (SA, p.r25, emphasis added). In a situation in which one needs to dwell in a field, which is exponentially expanding, speeding up of action becomes a natural and even rational temporal strategy. Indeed, due to the possibilities of smartphones and new ICTs (such as wearable technologies), immediate response, reaction and continuous, flexible availability are now rapidly establishing themselves as social obligations and even penetrate work ethic. Real-time connectivity and 24/7 availability not only stand at the centre of the experience of permanent distraction but also seem to render, as Jonathan Crary (2013) notes, human sleep as the last languishing "acceleration-less" zone.

Rosa identifies four manifestations of the heightening pace of modern life: "the speeding-up of individual actions, the elimination of breaks, the temporal overlapping of activities (multi-tasking), and the replacement of temporally costly with time-saving activities" (SA, p.I28-129)7. The feeling that one's life is getting ever faster is anchored in the "fear of missing out" and the "compulsion to adapt" (SA, p.I34) which do not necessarily originate only in the changing rhythms of technologically sped-up communication, circulation, production, etc. as mentioned above. Here Rosa touches upon the cultural origins of why people want—and opt for—acceleration (for instance, the compulsion to realize a good "worldly" life by living faster). Also, Rosa notes an important feature here: not having time, being busy, and being constantly in rush also "signals desirability and productivity" (SA, p.I35). Drawing on Niklas Luhmann, Rosa acknowledges another noteworthy and highly relevant facet: that the order of values is increasin-

7 At the same time, multi-tasking, which is ultimately a version of "temporal congestion", also slows things down. Carrying out too many activities/actions at once slows down the pace of each. 
gly structured through temporal perspective, i.e. it is the immediate problem that becomes the most important one. In other words "the urgency of the fixed term" (SA, p.I40), short-term priorities and deadlines are an overwhelming consideration structuring individual and institutional time schedules in a late modern society.

Each form of acceleration - technological acceleration, acceleration of social change and acceleration of pace of life-is propelled by a distinct "motor": economic (capitalist logic), cultural (secularism; the early modern promise of speed) and/or socio-structural (functional differentiation of modern society) (see SA, p.160-185). Simultaneously, social acceleration is also characterized by a self-reinforcing acceleration feedback loop (SA, p.I5I-159), which, in interplay with external motors, shapes the temporal structure of modern life. Yet, social acceleration is a highly differentiated and uneven phenomenon. Notwithstanding Rosa's internally coherent theoretical model whose subtle interconnections cannot be fully exposed here, an important caveat is made: not everything accelerates in modern society. Movement and inertia are dialectically intertwined in the process of modernization. Also, and importantly, there are processes and social instances that remain constant or even decelerate: natural limits of speed (biological rhythms: i.e. a cold and pregnancy cannot be sped-up); oases of deceleration (social and geographical niches not touched by acceleration); slowdown can be also a dysfunctional and unintended consequence of acceleration (the emblematic example of traffic jam). Also, there are two forms of intentional deceleration: first, there is slowness as an ideology (resistant Slow Food Movement); second there is slowdown as a strategy for acceleration (functional time-outs, moratoria, "recharging" techniques of time management) (SA, p.80-90). Finally, there is cultural and structural rigidity (SA, p.278-289), where underneath the volatile and hyper-accelerated transmissions, transactions and mobilities, there is standstill and inertia. Contemporary capitalist modernity can, in fact, be seen in terms of a relationship between the dynamic process of technological innovation (ever intensifying and extensifying production and consumption as well as ever tighter proliferation of communication technologies into the individual lifeworld), the static principles of flexible accumulation and the rather deepening class antagonisms: these features of acceleration societies seem to remain more-or-less unchanged.

\section{Tensions and paradoxes}

By advancing the theory of social acceleration Rosa aims to capture and explain a great paradox of modernity. On the one hand, technological acceleration has promised to "free-up" time, to "save time"- this is one of the key features of many technological and organizational devices. Countless modern inventions were simply intended to save physical effort and time (see also Tomlinson, 2007, p.2I-22). However, despite this promise, modern society is also characterized by dramatic decrease of temporal resources, which is widely reported in empirical studies on time-use (SA, p.r22-I3I). 
How to explain such a paradox? Building on Newtonian physics, technical-technological acceleration can be defined as "an increase in quantity per unit of time" whereby "various things may serve as quantity measured: distances travelled, total number of communicated messages, amount of goods produced... or the number of jobs per working lifetime or change in intimate partners per year or action episodes per unit of time" (SA, p.65). Modernity is then characterized by the exponential growth of these measured quantities: the world's population, the growth of cancer cells, the diffusion of commodities and technological innovations-including scientific publications, internet connections, and emails sent (ibid.). Simultaneously, in modernity the activities of communication, transportation, consumption, and production happen not only faster but transactions and exchanges occur more frequently, even though in themselves they rarely display "intrinsic tendencies of growth" (SA, p.66). Rosa explicates further: "In itself the capability of producing a given quantity of goods faster is independent of any escalation of production" (ibid.). In other words, the fact that we can communicate, travel, produce, etc. faster does not automatically or logically mean that we have to pursue these activities more often.

Modern society can be perceived as acceleration society insofar as the rates of growth (the quantity of produced commodities and services, the amount of transmitted messages and information units, and the number of distances covered) exceed the rates of acceleration of the given processes (technologically possible acceleration, the very activity that is sped-up). This is associated with the fact that "we produce, communicate, and transport not just faster but also more than in earlier social epochs" (SA, p.67-68, emphasis original). Simply put, the possibility to cover a distance from A to B faster does not imply that one will travel less. The same goes for multiplication of options, possibilities and the volume of information readily accessible through Internet nowadays. Acceleration society is a society that is characterized by the simultaneous ability to cover processes faster in relation to time and the parallel qualitative rise of commodities, information, exchanges to be consumed, processed, and communicated. This apparent paradox serves a strong explanatory purpose: that, on the one hand, time scarcity purports more speed and therefore drives the need for ever-faster time saving technological invention, on the other, the tension between rates of growth and rates of acceleration essentially explains why we tend to perceive the world as ever-faster (SA, p.I52-I59).

Another kind of temporal asynchronicity Rosa highlights emerges between the fast latemodern structural processes prescribing time horizons and patterns, and the allegedly slow and inflexible agents who have difficulties with accommodating the accelerating pace of modern era. Moreover, differing temporal orders and patterns stand for the paradigmatic perspective, which allows one to rethink the mediation between structure and agency — as mentioned above. Further conceptual move, then, lies in two epochal interpretations of modernity. In the first instance, Rosa notes that popular, as well as 
academic, diagnoses of time highlight acceleration as modernity's principal characteristic. In the second instance, diagnoses of time throughout modern era have stressed its rigidity and deep structural standstill. On a more experiential level, the "over stimulation and task overload" is accompanied by "uneventful boredom of modern life" (SA, p.I5, also p.44-45). Currently, this experiential tension manifests itself in the expectations posed by the imperative of increasing productivity, performance, growth and simultaneously rising of "time standing still" with pathological consequences such as anxiety, depression and phobias (in psychological terms) and alienation, disenchantment and anomie (in sociological terms). In the academic world, for instance, this might well be concerning early career researchers who are expected to produce increasing numbers of publications to even stand a chance in the higher education job market. This results in many "silencing techniques" preventing individual academics to openly voice their concerns about the current higher education realities (Gill, 2009), and, rather than publications, this situation generates increasing levels of depression and guilt.

The temporal asymmetry also holds true structurally where different speeds of social subsystems encounter each other. The rhythms of education or democratic polity simply cannot keep pace with the real-time tempo of algorithms-driven financial capitalism.Rosa calls this temporal phenomenon "the simultaneity of the non-simultaneous" (SA, p.i9, see also p.I I4-I I5). ${ }^{8}$ This theme begins to resonate in social and political-democratic theorizing (Glezos, 20ı2; Hope, 20ıг; Laux, 20ıг; Scheuerman, 2004) and accounts for one of the most viable and promising dimensions of the Rosa's theoretical scheme. Different temporalities define distinct generations, social worlds, fields, systems, and administrative apparatuses, which counteract and mutually exclude one another rather than coexist. In the realm of new electronic/communication technologies this perspective reveals an emerging kind of social inequality-generations of people born in the Internet age and the stock of skills and knowledge they acquire seems incompatible with older generation's "slower" modes of engagement and communication. It can be speculated that technosavvy fast users and consumers of ever-changing hardware and software- those digitally literate-will be (and already are) in a structurally advantageous position in contrast to those lacking, or resisting the acquisition of, comparable skills.

\section{Polemical considerations}

Despite many caveats and the argument's internal complexities one has an impression that acceleration constitutes a mega-force in its own right-happening "behind the backs of actors" (SA, p.315) — and that, in various ways, and with different intensities, it engulfs the entirety of human and social life. Nothing and nobody is spared: social acceleration has affected "the ways of being" (SA, p.I46-I48). Rosa maintains: "the modern acceleration 
dynamic not only transforms the way subjects do things but also the way they are, i.e. their identities or the way they relate to themselves, because these are constituted by those relationships and actions" (SA, p.I45, emphases original). Social acceleration is thus presented as the "iron-cage" of (late) modernity due to its autonomous dynamic (SA, p.I57). It is not the case that all social sectors and segments and geographical regions are caught up in the transformative dynamic of acceleration to the same extent, yet the logic of acceleration not only "determines the structural and cultural evolution of modern society" (SA, p.279), but also accounts for "the unbridled onward rush into an abyss" (SA, p.322).

This structural position is, however, slightly problematic. According to the acceleration logic it seems that individuals are more or less passive victims of larger temporal structures and horizons. However, individuals can, and often do, step back, retreat and make their own sense of the surrounding temporal (accelerating) social structures: "rather than be at the mercy of forces beyond their ken or control [...] people exercise a measure of [temporal] self-determination or agency" (Flaherty, 20I I, p.3). Moreover, individuals often inhabit different "zones of time" (Glezos, 20I2, p.26-30) and variegated "timescapes" (Adam, 1998). This is not to say that Rosa neglects the importance of temporal intentionality (see Flaherty, 20I I, p.2-I3, p.24, p.77, p.133), but his account implicitly maintains that individuals have to make a bigger effort to regulate their schedules in the conditions of socially accelerating society. Flaherty, opening the constitutive debate of the social sciences between "internal" subjectivity/agency and "external" structural/systemic constraints notes that "thought, experience, feeling, judgement, choice, will, value [and] emotion" (ibid., p.4) all stand for significant variables in the social analysis of time experience. Furthermore, he notes that rather than another round of epistemological dispute a much more modest task is overdue: an empirical investigation of acceleration and temporal agency (Flaherty, 20 I; see also Wajcman, 2008). Indeed, Rosa's account has already provoked some circumscribed empirical inquiries (e.g. Ulferts et al., 20I3) largely acknowledging acceleration as a plausible experiential modality, yet other studies present more ambivalent arguments on the experience of acceleration (Vostal, 20I4). The investigation of acceleration experience then becomes a methodological and theoretical issue. Alongside inquiries into acceleration experience, a semantic reconstruction of the category of acceleration might account for a fruitful and conductive research avenue (see Vieira, 20II). In this sense, acceleration can be understood figuratively and substantially. Let's begin with the former. Customization and operationalization of specific language terms into analytical categories is not a deficiency of social inquiry, as social science can barely flourish without a degree of constructive imagination. In Rosa's conception then, the time shortage, rush, hurry, and chronic time pressure-all of those either causes or effects of acceleration experience-most often stand for sedentary acceleration (Tomlinson, 2007, p.3). Paradoxically, in most cases, and in the evidence Rosa uses, this is the prevalent type of acceleration experience: sedentary, mostly motionless 
phenomenological rather than directly physical time experience. In fact, two sedentary phenomenological time experiences can be identified. In his exemplary account Daniel Kahneman (20II) notes that the terminology of fast vs slow holds an important explanatory and analytical purchase for understanding of human mind and thinking. Kahneman argues that the complex structure of moral judgement and decision-making is composed of fast (intuitive, quick, gut-like, emotional-System I) and slow (deliberate, concentrated, rational, contemplative-System 2) interacting modalities ${ }^{9}$.

Yet, next to the sedentary experience, acceleration is also-and in the public discourse perhaps predominantly so-related to physical movement and its increasing rate. How many times a day or a week we literally (i.e. physically) experience acceleration, that is, physical movement in space in relation to time? It is possible that some individuals do physically speed-up due to time pressure, however most of us, I would argue, experience physical acceleration mostly physiologically - in a car, on a (motor)bike, on the plane, on a train, on a rollercoaster (Balint, 1959; Duffy, 2009; Kern, 2003; Shin and Divall, 20I2). Here we encounter a different analytical focus whilst looking at acceleration. In this sense, can it be the case that acceleration might be an energetic experience and inform individual, and even collective, capacities as opposed to being a merely societal force taxing and shaping the agency of modern subjects and institutions?

Acceleration in Rosa's sense is understood as a negative and oppressive phenomenon. This surely is a tremendously relevant perspective, yet-from a different theoretical standpoint-acceleration is also likely to be perceived as a positive instrument or even a goal in its own right. Indeed, Rosa's approach "shares the basic intention of [The Frankfurt School's] social criticism” (SA, p.3 I), which, at the same time, prohibits him from seeing acceleration differently than a new form of social domination (this approach is also evident in other contributions to the critical social theory of speed, see e.g. Hassan, 2008; 20I2). Also, Rosa only partially exposes the reasons why modern individuals and even institutions might opt for acceleration; let alone the reasons and explanations why individuals may embrace and find acceleration thrilling, both in a literal and figurative sense. My own work, which scrutinizes the structure of the acceleration experience in contemporary academia, argues that academics not only experience oppressive acceleration as a result of increasing workload and time pressure, but they also oftentimes convey another type of accelerative moments (such as aha-moments, brainstorming, discovery) and even consider them as integral parts of academic life (see Vostal, 20I4). It must be noted that, although Rosa's theory does not explicitly refuse the possibility that there are gains and opportunities associated with acceleration (see for instance Rosa, 2010a, p.99; 2010b; SA, p.134, p.319), and that in early modernity acceleration used to be an instrument of self-

9 Fast and effective decision-making, brain "short-cuts", intuition and heuristics were extensively examined by Gigerenzer (2007). 
determination that in late modernity have metamorphosed into new form social domination, positive appreciation of acceleration has almost no place in his argumentation.

Due to the density, complexity and various conceptual and theoretical interdependencies-together with the highly-developed prose Rosa and his translator master-one cannot resist asking this simple question: if the authors are correct and acceleration is such a tremendous force affecting, in varying degrees, the majority of spheres of social life, where did Rosa and his translator craft the time to write-and research, (re)read, revise, edit - and translate such a meticulous and brilliant study of 470 pages? How did they find a temporal "snapshot", how did they craft their de-accelerated space in the conditions of an acceleration society, that allowed them to write and respectively translate this great book? Rosa, in fact, indirectly reflects on this problem: "Everywhere it seems like there is no time available for long-term goals - in the example of the scholar, for instance, writing her new book-because of the constant pressure of little demands in the meantime, things which are very often directly related to keeping open opportunities" (SA, p.i36). Nevertheless, this apparently is not Rosa's case. He did, after all, find time to write his book (surely we cannot know what the psycho-phenomenological "costs" were). Highlighting this point, I intend to open up the pressing question as to whether or not contemporary academia still holds - albeit minimally - some characteristics of a time zone that enables the pursuit of long-term and time-demanding goals, ambitions and life projects (of scientific, scholarly and educational/pedagogical nature). Rosa's monograph, and sustained work on his extraordinary acceleration theory, can be seen as a proof that this possibility still-perhaps residually though-exists.

Notwithstanding these minor objections, there is no doubt Rosa's study exhibits all the features of ground-breaking social theorizing: it offers serious non-cursory theoretical scheme explaining why social acceleration is a relevant concern for social analysis; it develops meticulous conceptual and causal theoretical and explanatory connections; the conceptual building blocks are carefully defined and demarcated and various interreferences are made; rigorous statements together with clear and systematic argumentative threads guide the reader into the complex interdependencies of causes and consequences of acceleration, its logic and manifestations, its pathologies and paradoxes. Moreover, the study is larded by operationalized secondary empirical studies and develops an original critical standpoint. Not only that: it offers an interpretative matrix for modernity and the reader, after finishing the book, not only does one have the impression that the present social reality can be explained through a social acceleration perspective, but also that the theory has great conductive revelatory potential. This makes the study extremely valuable-especially in comparison with the often prophetic and apocalyptic writings of Virilio, or on more popular science grounds, in comparison to the interesting but non-scholarly writings on acceleration of James Gleick, both of whom many social scientists keep connecting with the problem of acceleration. Rosa 
should indeed become a new figure to be widely associated with acceleration, replacing Virilio and popular science writings and thus elevating the theme of acceleration from enigmatic speculationism and sophisticated yet non-analytical journalism to more social scientifically rigorous and analytical waters.

Acknowledgements: I thank Benoît Pelopidas and reviewers of Revue européenne des sciences sociales for their encouragement and insightful comments on an earlier version of this essay. I am also grateful to the Institute of Sociological Studies at Charles University in Prague for hosting me as a postdoctoral researcher during the writing of the essay.

\section{Bibliography}

ADAM B., 1998, Timescapes of Modernity: The Environment and Invisible Hazards, London, Routledge.

BALINT M., 1959, Thrills and Regressions, London, Karnac.

BOURDIEU P. 1998 (1996), On Television, New York, The New Press.

CONNOLLY W., 2002, Neuropolitics: Thinking, Culture, Speed, Minneapolis, The University of Minnesota Press.

CRARY J., 2013, 24/7: Late Capitalism and the Ends of Sleep, New York, Verso.

DIVALL C., SHIN H., 2012, "Cultures of speed and conservative modernity:

Representations of speed in Britain's railway marketing", in Trains, Culture, and Mobility: Riding the Rails, B. Fraser and S.D. Spalding (eds), Lanham, Lexington Books, p.3-26.

DUFFY E., 2009, The Speed Handbook: Velocity, Pleasure, Modernism, Durham, Duke University Press.

FAHERTY M., 20II, The Textures of Time: Agency and Temporal Experience, Philadelphia, Temple University Press.

GIGERENZER G., 2007, Gut Feelings: Short Cuts to Better Decision Making, London, Penguin.

GILL R., 2009, "Breaking the silence: the hidden injuries of neo-liberal academia" in Secrecy and Silence in the Research Process: Feminist Reflections, R. Flood \& R. Gill (eds), London, Routledge, p.228-[244].

GLEZOS S., 2012, The Politics of Speed: Capitalism, the State and War in an Accelerating World, London, Routledge.

HASSAN R., 2008, The Information Society, Cambridge, Polity Press.

-, 2012, The Age of Distraction: Reading, Writing, and Politics in a High-Speed Network, Economy, New York, Transaction Books. 
HOPE W., 20 II, "Crisis of temporalities: Global capitalism after the 2007-2008 financial collapse", Time \& Society, 20-I, p.94-1।8.

KAHNEMAN D., 20II, Thinking, Fast and Slow, London, Penguin.

KERN S., 2003, The Culture of Time and Space: 1880-1918, Cambridge, Harvard University Press.

LAUX H., 20 II, "The time of politics: Pathological effects of social differentiation", Time \& Society, 20-2, p.224-240.

ROSA H., 2003, "Social acceleration: Ethical and political consequences of a de-synchronized high-speed society", Constellations, 10-I, p.3-33.

-, 2005a, Beschleunigung: Die Veränderung de Zeitstrukturen in der Moderne, Frankfurt am Main, Suhrkamp.

-, 2005b, "The speed of global flows and the pace of democratic politics", New Political Science, 27-4, p.445-459.

-, 2010a, Alienation and Acceleration: Towards a Critical Theory of Late-Modern Temporality, Malmö, NSU Press.

-, 2010b,"Full speed burnout? From the pleasures of the motorcycle to the bleakness of the treadmill: The dual face of social acceleration", International Journal of Motorcycle Studies, 6-I, online: <http://ijms.nova.edu/Spring20I0/IJMS_Artcl.Rosa.html> (last visited March 2014).

-, 2012a, Aliénation et accélération: Vers une théorie critique de la modernité tardive, Paris, La Découverte.

-, 2012b, Weltbeziehungen im Zeitalter der Beschleunigung, Frankfurt am Main, Suhrkamp.

-, 2013a, Accélération: Une critique sociale du temps, Paris, La Découverte.

-, 2013b, Beschleunigung und Entfremdung: Entwurf einer kritischen Theorie spätmoderner Zeitlichkeit, Berlin, Suhrkamp.

-, SCHEUERMAN W. (eds), 2009, High-Speed Society: Social acceleration, Power, and Modernity, Pennsylvania, The Pennsylvania State University Press.

SAVAGE M., 2009, "Against epochalism: An Analysis of conceptions of change in British Sociology", Cultural Sociology, 3-2, p.217-238.

SCHEUERMAN W., 2004, Liberal Democracy and the Social Acceleration of Time, Baltimore, The Johns Hopkins University Press.

ULFERTS H., KORUNKA C., KUBICEK B., 2013, "Acceleration in working life: An Empirical test of sociological framework", Time \& Society, 22-2, p. I6।-185.

VIEIRA R.A., 20 II, "Connecting the new political history with recent theories of temporal acceleration: Speed, politics, and the cultural imagination of fin de siècle Britain", History and Theory, 50, p.373-389. 
VOSTAL F., 2014, "Academic life in the fast lane: The experience of time and speed in British Academia", Time \& Society, Published OnlineFirst, 20 January 2014 : <doi:I0.1 177/096|463X|3517537>.

WAJCMAN J., 2008, "Life in the fast lane? Towards a sociology of technology and time", British Journal of Sociology, 59-I, p.59-77.

YLIJOKI O-H., 2013, "Boundary-work between work and life in the high-speed university", Studies in Higher Education, 38-2, p.242-255.

ZERUBAVEL E., 1985, Hidden Rhythms: Schedules and Calendars in Social Life, Los Angeles, University of California Press. 
